\title{
Histological Evaluation of the Emerging Role of Adipose Stem Cells-Derived Exosomes in Cutaneous Wound Healing in Albino Rats
}

Original Article
Dalia Ibrahim Ismail and Alshaymaa Gamal Aboulkhair

Histology Department, Faculty of Medicine, Cairo University, Cairo, Egypt

\begin{abstract}
Background: Skin is the largest protective organ in the body, but it is frequently injured by either acute or chronic wounds. Prolonged healing and scar formation are two major challenges in treating wounds, resulting in physical, mental and socioeconomic burden to the affected subjects. Exosomes (Exos) are naturally secreted vesicles playing a vital role in the transfer of RNA to neighboring or distant recipient cells and there are numerous on-going studies on their role of in tissue regeneration and wound healing.

Aim of the work: Evaluation of the efficiency of Exos derived from adipose stem cells on cutaneous wound healing in adult male albino rats.

Materials and Methods: Thirty-four rats were divided into three groups; Group I: control. Group II: a dorsal cut wound $(1.5 \times 1.5 \mathrm{~cm})$ was done to each rat. Group III: the same wound was done and rats were injected with $200 \mu$ PKH26-labeled Exos intravenously. Rats were sacrificed after 21 days. Skin sections were subjected to hematoxylin and eosin (HandE), Mallory's trichrome and orcein stains, alpha smooth muscle actin ( $\alpha$-SMA) and Ki67 immunohistochemical stains.

Results: Skin sections from group II showed scar formation, lost epidermal layers and hair follicles. There was significant increase in collagen fibers and $\alpha$-SMA immunoreaction, with significant decrease in elastic fibers and Ki67 immunoexpression compared to the control. In group III, the skin revealed almost normal histology, significant decrease in collagen fibers and $\alpha$-SMA, with significant increase in elastic fibers and Ki67 immunoreaction compared to group II.

Conclusion: Exos injection has demonstrated a beneficial effect on cutaneous wound healing and could prevent scar formation in adult male albino rats.
\end{abstract}

Received: 20 July 2018, Accepted: 24 July 2018

Key Words: Cutaneous Scar; exosomes; myofibroblast; skin Wound; wound Healing.

Corresponding Author: Dalia Ibrahim Ismail, M.D, Histology Department, Faculty of Medicine, Cairo University, Cairo, Egypt, Tel.: +20 1005050870, E-mail: drdaliaibrahim@hotmail.com

ISSN: 1110-0559, Vol. 41, No. 4

\section{INTRODUCTION}

Cutaneous wound healing requires a well coordinated integration of complex molecular and biological events involving different cell types, extracellular matrix (ECM) and growth factors. In spite of multiple active therapeutic studies, no current effective treatment has been determined for scarless wound healing ${ }^{[1]}$. Wound healing involves an overlapping cascade of events that can be distinguished into four phases. These include: haemostasis, where blood loss stops. Inflammatory phase, in which there is immune cells infiltration to remove cellular debris and combat infection. Proliferative phase, keratinocytes and fibroblasts present at the wound margins migrate into the wound and increase in number to restore the barrier function of skin. Remodeling phase, during which reorganization of the dermis occurs and the ECM, laid down during the earlier phases of the healing process, is remodeled to strengthen the wound area by reducing the scar tissue ${ }^{[2]}$.

Myofibroblasts (MFs) are key players in maintaining skin homeostasis and coordinating physiological tissue repair. MFs are embedded in the sophisticated ECM they secrete, and an interactive complex dialogue exists between them and their microenvironment. In addition, MFs secrete matrix metalloproteinases and tissue inhibitors of metalloproteinases that are capable of remodeling this ECM. In pathological situations as excessive scarring or fibrosis, this dialogue is altered or disrupted, leading to repair defects. Therefore, the intimate dialogue between MFs and their microenvironment represents an attractive domain for researchers to characterize new therapeutic targets and drugs able to prevent or treat pathological skin alterations ${ }^{[3]}$. The fully differentiated MFs express smooth muscle-specific cytoskeletal protein, alphasmooth muscle actin ( $\alpha$-SMA), which is used to define the MFs phenotype ${ }^{[4]}$. Also it was established that excessive collagen protein deposition by MFs is the causative factor for scar formation ${ }^{[1]}$.

Recently there have been advances in stem cell transplantation therapy and tissue engineering, investigating the role of microRNA in tissue regeneration and also the 
role of extracellular vesicles (EVs) in wound healing. There are different subtypes of vesicles with overlapping size, density and composition. Because of the lack of specific markers for these different subtypes, the International Society of Extracellular Vesicles recommended the term EVs to describe the preparations of vesicles from body fluids and cell cultures. EVs include exosomes (Exos), microvesicles, ectosomes, prostasomes and oncosomes ${ }^{[5]}$. Moreover the involvement of EVs in wound healing has been proved and described for coagulation, cell migration and proliferation and angiogenesis ${ }^{[2]}$.

The Ki67 protein is a marker associated with cell proliferation, as it is accompanied by ribosomal RNA transcription. It is prominently present during all stages of cell division except G0 phase. The Ki67 antigen is detected within the cell nucleoplasm during interphase, and then it is relocated to the chromosomal surface during mitosis ${ }^{[6]}$.

Exosomes (Exos) are the smallest subtype of EVs with diameters between 40 and $100 \mathrm{~nm}$ and cupshaped morphology. Although their biogenesis is not fully understood, it is generally accepted that Exos are formed and developed via the endocytic pathway and are released to the extracellular environment by exocytosis ${ }^{[7]}$. The formation and release process begins when fluids, macromolecules, solutes and plasma components are internalized by various endocytic pathways into transport vesicles. Then these vesicles fuse with one another or with an existing endosome to form early endosomes. Early endosomes collect proteins and other components and develop into late endosomes, which may recycle its components back to the plasma membrane or may be degraded by lysosomes ${ }^{[8]}$. Alternatively, these late endosomes may become multi-vesicular bodies that fuse with cellular membrane and release Exos. While much remains unknown about Exos biogenesis, their formation and release are tightly regulated by multiple signaling mechanisms ${ }^{[9]}$. Moreover, they represent an essential medium for intercellular communication as a variety of microRNAs and proteins are sorted in them ${ }^{[10]}$. Exos have been proved to assist in tissue repair due to their advantages of high stability, easy control of dosage and concentration, homing effect and non-immune rejection ${ }^{[1]}$.

Consequently, the present work was conducted to study the promising role of adipose stem cells-derived exosomes (ASCs-Exos) in the healing of skin full-thickness excision wounds in adult male albino rats; this was done using histological and immunohistochemical methods.

\section{MATERIALS AND METHODS}

\section{Materials}

\section{Isolation and culture of ASCS}

This was carried out according to ${ }^{[12]}$. Rats' subcutaneous adipose tissues samples were washed with phosphate buffered saline (PBS, Sigma Aldrich, product no. P5368, USA) to remove red cells. Then they were chopped into small pieces of about $25-50 \mathrm{~mm} 3$ and digested with $0.1 \%$ collagenase type I (Sigma Aldrich, CAS 9001-12-1, USA) at $37^{\circ} \mathrm{C}$ for $60 \mathrm{~min}$. To obtain a single cell suspension, the digested material was filtered through a $100 \mu \mathrm{m}$ mesh filter to remove tissue debris. The cell suspension containing ASCs was centrifuged at $1000 \mathrm{rpm}$ for $5 \mathrm{~min}$, and the pellet was resuspended in specific MSCs culture medium (Gibco, cat. no.12563-029, UK). ASCs are known to exhibit positive surface antigenicity for CD13, CD44, CD90, and CD105 and negative surface antigenicity for CD14 and CD34 ${ }^{[13]}$.

\section{Exosomes preparation and isolation}

This was done as previously described ${ }^{[14]}$. Cell lines were cultured until 70\% confluence, washed once by Dulbecco's phosphate buffered saline (DPBS, cat. no.14190250) and incubated with fresh serum-free medium for $30 \mathrm{~min}$ at $37^{\circ} \mathrm{C}$ and $5 \% \mathrm{CO}$. Then, the medium was replaced by serum-free medium (cat. no. A1033201) and returned to the incubator. Afterwards, the cell-conditioned media were collected and Exos were isolated by differential centrifugation as follows: $300 \times \mathrm{g}$ for 10 minutes to remove cells, 2,600 $\times \mathrm{g}$ for 10 minutes to remove residual cells and debris, 10,000 $\times \mathrm{g}$ for 60 minutes to remove microvesicles, and 100,000 $\times \mathrm{g}$ for 2 hours to collect nano-scaled vesicles in pellets. The resulting pellet was resuspended, washed once in Dulbecco's Modified Eagle's Medium (cat. no.12491015) and repelleted at $100,000 \times \mathrm{g}$ for 2 hours. Once isolated, nano-scaled vesicles were resuspended in DPBS and kept on ice. All chemicals were purchased from Gibco, UK.

\section{PKH26 labeling of Exosomes}

It was done according to Sigma protocol, using PKH26 (product no. PKH26GL). PKH26 was diluted in diluent $\mathrm{C}$ (product no. CGLDIL) for a final concentration of 1 $\mathrm{x}$ 10-6 M, and then was mixed with EXs resuspended in diluent $\mathrm{C}$. The Exos dye suspension was incubated for 5 min, and the excess dye was removed by centrifugation and resuspended in $\mathrm{PBS}^{[1]}$. The dye and diluent $\mathrm{C}$ were purchased from Sigma Aldrich, St. Louis, MO, USA.

\section{Animals}

All the animals' experiments were done in accordance with the guidelines approved by the Animal Use Committee of Cairo University. Thirty-four adult male albino rats weighing 180-200 gm were housed in the laboratory animal house unit of Kasr Al-Ainy Faculty of Medicine, Cairo University. They were provided with ordinary rat chow, bred and housed in standard stainless-steel cages at a $12 \mathrm{~h}$ cycle of light and dark, a room temperature of $24 \pm 2$ ${ }^{\circ} \mathrm{C}$, and humidity maintained at $50 \%$. All animals were kept under the same environmental conditions and had free access to water and food.

\section{Rats' skin wound model and treatment}

Rats were anesthetized by intraperitoneal injection of $50 \mathrm{mg} / \mathrm{kg}$ pentobarbital, and after shaving the dorsal hair at the mid back, the skin was disinfected with $70 \%$ ethyl alcohol and a full-thickness excision wound (the fascia 
covering the muscle was exposed), with size (1.5 x 1.5 $\mathrm{cm})$ was created to each rat. The wound was cleansed with betadine but no systemic antibiotic was given to the animals. Then rats were randomly assigned to two groups; and half of them were intravenously injected with $200 \mu$ PKH26-labeled exosomes ${ }^{[15,16]}$.

\section{Experimental design}

The thirty-four adult male albino rats were divided into three groups as follows:

- Group I (Control group): ten rats received standard rat chow diet and water.

- Group II (Excision wound group): ten rats having a full-thickness excision wound with size $(1.5 \times 1.5 \mathrm{~cm})^{[15]}$ (Fig. 1A).

- Group III (Exos-treated group): fourteen rats having a full-thickness excision wound as in group II followed immediately by intravenous injection of $200 \mu$ PKH26-labeled exosomes ${ }^{[15,16]}$.

\section{Methods}

Four rats from group III (Exos-treated group) were sacrificed on day 7 post-injection, and the rest of rats were sacrificed on day 21 , all by intraperitoneal injection of pentobarbital $50 \mathrm{mg} / \mathrm{Kg}^{[17]}$. The skin wound tissues were collected and fixed immediately in $10 \%$ buffered formalin for histological and immunohistochemical studies. Paraffin embedded tissues were cut into sections of $5 \mu \mathrm{m}$ thickness and were subjected to the following:

- Hematoxylin and Eosin (HandE) stain ${ }^{[18]}$.

- Mallory's trichrome stain for collagen fibres ${ }^{[19]}$.

- Orcein stain for elastic fibers ${ }^{[19]}$.

- Immunohistochemical staining for alpha-smooth muscle actin ( $\alpha$-SMA) (Bancroft and Gamble, 2008). It is a mouse monoclonal antibody (Abcam, ab7817, USA) used to define the myofibroblast phenotype. It appears as brown cytoplasmic reaction.

- Immunohistochemical staining for Ki67 (Bancroft and Gamble, 2008). It is a rabbit polyclonal antibody (Lab Vision Neomarker, RB-9043-R7, USA), used as a marker for proliferation. It appears as brown nuclear reaction.

- Negative control slides for both immunohistochemical stains were done by omitting the step of primary antibodies.

- Examination of PKH26 labeled Exos by fluorescent microscope (Olympus, Japan) in unstained sections of rats from group III that were sacrificed on day $7^{[1]}$.

\section{Morphometric study}

Using " Leica Quin 500" software image analyzer computer system (Leica image system Ltd; Cambridge, England). From each section, 10 non overlapping randomly-chosen fields were examined using an objective lens of magnification $\mathrm{x} 10$, i.e. at total magnification $\mathrm{x} 100$. The following parameters were measured:

- Epidermal thickness.

- Dermal thickness

- Area percent of collagen fibers.

- Area percent of elastic fibers in orcein stained sections.

- Area percent of $\alpha$-SMA immunoexpression.

- Number of Ki67 immunoreactive cells

\section{Statistical analysis}

It was done for the morphometric results. Data were expressed as mean and standard deviation (SD) for the quantitative variable. Data were statistically analyzed using statistical package SPSS version 16 (SPSS Inc., Chicago, USA). Comparisons between groups were done using ANOVA (analysis of variance) followed by post-Hoc multiple comparisons test. The results were considered significant when $p<0.05^{[20]}$.

\section{RESULTS}

\section{Macroscopic examination of the skin wound areas}

Rats from group II (cut wound group) exhibited incomplete closure of the wound, epidermal loss, scar formation and hyperemia (Fig. 1B). Whereas rats from group III (Exo-treated group) had gross picture almost appeared as the control; complete epidermal coverage with appearance of hairs that was shaved (Fig. 1C).

\section{Histological results}

\section{HandE stained sections}

Skin sections from group I (control group) revealed normal histological structure for the epidermis and dermis. The epidermis was composed of keratinized stratified squamous epithelium 4-6 cell layers thickness. The stratum basale was formed of a single layer of basophilic columnar cells with basal oval nuclei resting on basement membrane; the stratum spinosum was formed of 2-3 layers of polyhedral cells with central rounded nuclei; whereas the stratum granulosum was formed of about 2-3 layers of flat cells with deeply basophilic granular cytoplasm and flat nuclei. Superficially, the stratum corneum appeared as a non cellular acidophilic keratin layer. Langerhans' cells appeared with cytoplasmic halo surrounding dark nuclei among keratinocytes. There was prominent dermalepidermal junction; i.e. the border between the epidermis and dermis was clearly demarcated. The dermis displayed normal thickness, and consisted of densely packed, thick bundles of collagen fibers. The papillary layer showed more capillaries and connective tissue cells, whereas the deeper reticular layer was composed of a denser more 
fibrous connective tissue. In addition, hair follicles with the associated sebaceous glands were seen. The hair follicles were cut in different directions and were observed in the mid to upper dermis and some were seen near to the hypodermis (Fig. 2 A and B).

Sections from rats of group II (excision wound group) showed some areas covered with thin epidermis formed of 1-3 cell layers thickness with reappearing keratin formation. Other areas displayed completely lost epithelial covering leaving only exposed basal lamina. The dermis showed markedly increased thickness, and contained thick bundles of collagen fibers occupying both the papillary and reticular layers (granulation tissue formation). The blood vessels, hair follicles andsebaceous glands could not be detected at the areas of granulation tissue (Fig. $3 \mathrm{~A}$ and B).

Examined skin of rats from group III (Exos-treated group) was almost similar to the control; it presented with apparently normal epidermis, there was complete epithelialization, prominent dermal-epidermal junction. The underlying dermis was of normal thickness and the papillary layer revealed blood capillaries and more connective tissue cells, whereas the reticular layer was composed of a dense fibrous connective tissue. In association, sebaceous glands and hair follicles were also present (Fig. 4 A and B).

\section{Mallory's trichrome stained sections}

Sections from both the control group (Fig. 5A) and group III (Fig. 5C) presented thin interlacing bundles of loosely arranged blue stained collagen fibers in the papillary dermis. In the reticular layer the collagen fibers appeared coarse, wavy irregular bundles with the presence of epidermal covering and skin appendages. Whereas sections from group II (Fig. 5B) showed dense thick coarse collagen bundles that occupied all the dermal thickness. There was neither epidermal covering, nor hair follicles nor sebaceous glands.

Orcein stained sections
Skin sections from group I revealed brick red thin elastic fibers in the papillary dermis that appeared in the form of fine interlacing network extending up to the dermal-epidermal junction. They appeared longer, thicker and branched in the reticular layer and condensed around the hair follicles (Fig. 6A). Group II exhibited no apparent elastic fibers in the granulation tissue (Fig. 6B). Whilst in group III, elastic fibers in the subepidermal area looked similar in their organization to that of the control group (Fig. 6C).

\section{Immunohistochemical results}

\section{aSMA immunohistochemical results}

Examined sections from control rats showed few brown immunoreactive cells in the dermis mainly around blood capillaries (Fig. 7A). As for group II, skin revealed widespread immunoreaction within the dermis and around capillaries (Fig. 7B). While in group III, there was moderate immunoreactive cells (arrows) scattered in the skin dermis, some of them were related to capillaries, hair follicles and sebaceous glands (Fig. 7C).

\section{Ki67 immunohistochemical results}

Skin sections of the control group showed scarce brown immunoreactive nuclei in the cells of epidermis and in the hair follicles (Fig. 8A). In sections from group II, there were few immunoreactive cells in the thin epidermal layer and the dermis (Fig.8B). Whereas group III displayed many brown immunoreactive nuclei in the epidermal cells especially in the stratum basale, and in the hairs follicles (Fig. 8C).

\section{Fluorescent results}

Unstained sections from group III (Exos-treated group) demonstrated homing of the PKH26 labeled Exos in the papillary and reticular layers of the dermis at day 7 (Fig. 9).

\section{Morphometric and statistical results}

Morphometric results are illustrated in Table 1.

Table 1: Mean values $( \pm \mathrm{SD})$ of morphometric parameters in the studied groups.

\begin{tabular}{|c|c|c|c|}
\hline \multirow{2}{*}{ morphometric parameters } & \multicolumn{3}{|c|}{ Mean values $( \pm \mathrm{SD})$} \\
\hline & GI (Control) & GII (Excision wound) & GIII (Exos-treated) \\
\hline Collagen area $\%$ & $9.19 \pm 1.34$ & $22.48 \pm 3.3^{*}$ & $14.31 \pm 1.2^{* \$}$ \\
\hline Orcin area $\%$ & $2.95 \pm 0.34$ & $0.22 \pm 0.23^{\square}$ & $2.73 \pm 0.41^{\#}$ \\
\hline SMA area $\%$ & $0.56 \pm 0.31$ & $3.73 \pm 0.54^{*}$ & $1.82 \pm 0.36^{* \$}$ \\
\hline Ki67 number & $4.2 \pm 2.2$ & $5.3 \pm 1.2$ & $28.6 \pm 5.2^{* \#}$ \\
\hline Epidermal thickness in $\mu \mathrm{m}$ & $20.41 \pm 2.4$ & $10.34 \pm 2.7^{\square}$ & $19.34 \pm 3.1^{\#}$ \\
\hline Dermal thickness in $\mu \mathrm{m}$ & $336 \pm 22.4$ & $616 \pm 30.5^{*}$ & $412 \pm 24.7^{* \$}$ \\
\hline
\end{tabular}



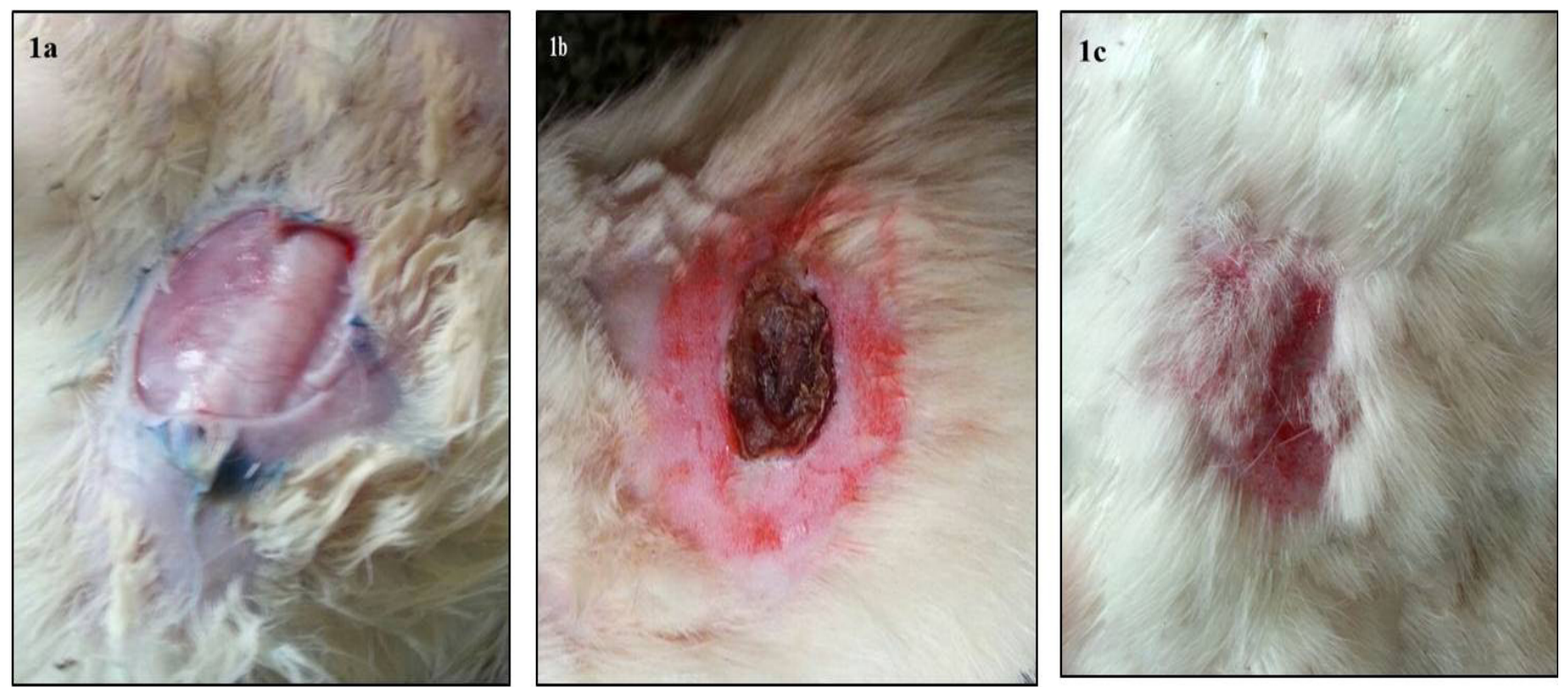

Fig. 1: Pictures for the wound area. (A) A full-thickness excision wound at the mid back of rats after shaving the dorsal hair. (B) Rats from group II (cut wound group) present incomplete closure of the wound, epidermal loss, scar formation and hyperemia. (C) Rats from group III (Exos-treated group) reveal complete epidermal coverage with the appearance of hairs.
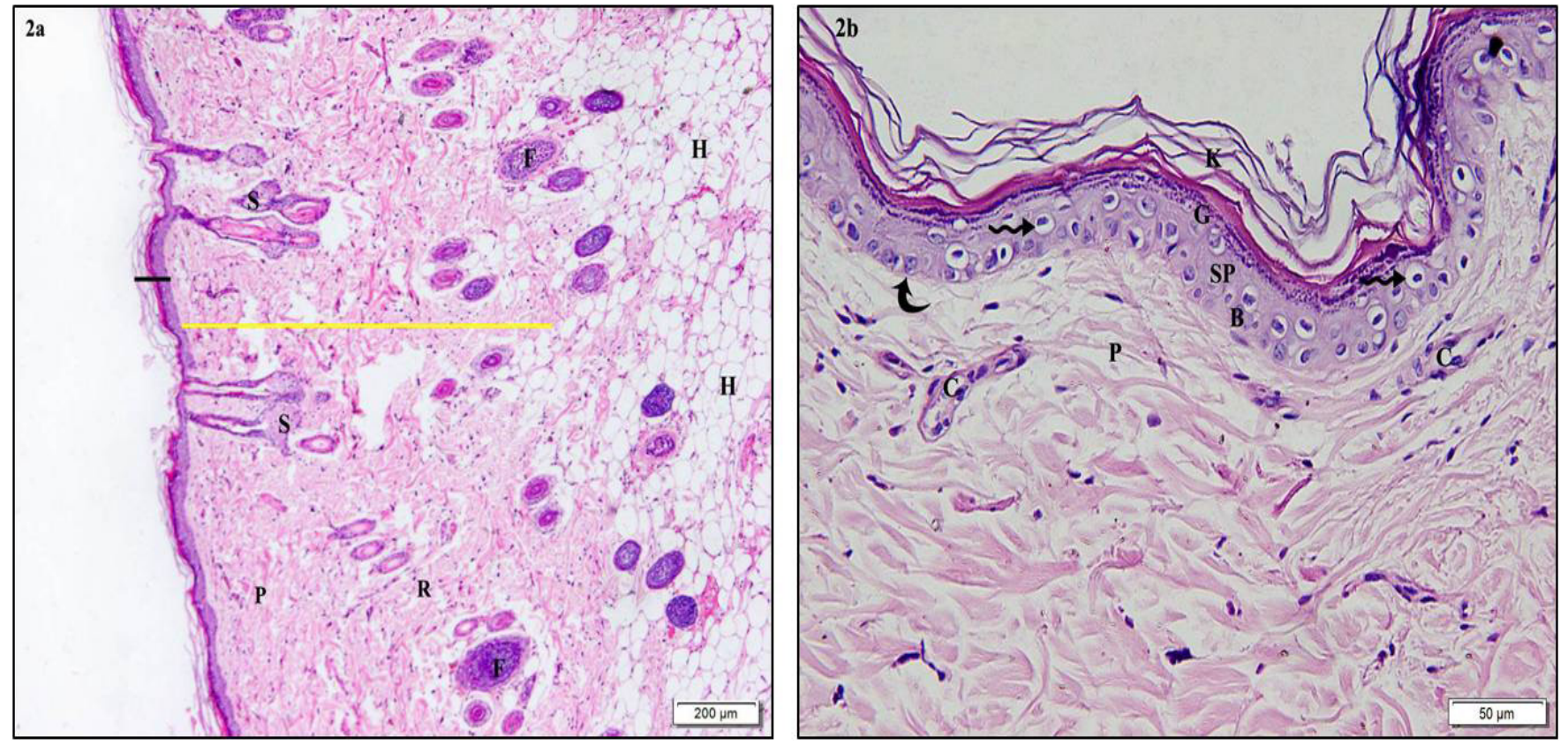

Fig. 2: Photomicrograph of a skin section from a control rat. (A) Shows normal epidermis formed of keratinized stratified squamous epithelium (black line) and dermis (yellow line). The dermis is of normal thickness and consists of superficial papillary layer $(\mathrm{P})$ and deeper reticular one (R). The lower part is occupied by hypodermis $(\mathrm{H})$ full of fat cells. Sebaceous glands $(\mathrm{S})$ and hair follicles $(\mathrm{F})$ are seen in the mid to upper dermis and some were seen near to the hypodermis $(\mathrm{H})$.

(B) Higher magnification shows normal epidermis formed of stratum basale (B), 2-3 layers of stratum spinousum (SP), 2-3 layers of stratum granulosum (G) and keratin (K). Langerhans' cells (wavy arrows) are found among the keratinocytes. Dermal-epidermal junction (curved arrow) and numerous blood capillaries (c) in papillary layer $(\mathrm{P})$ are seen (HandE, x100; x200) 

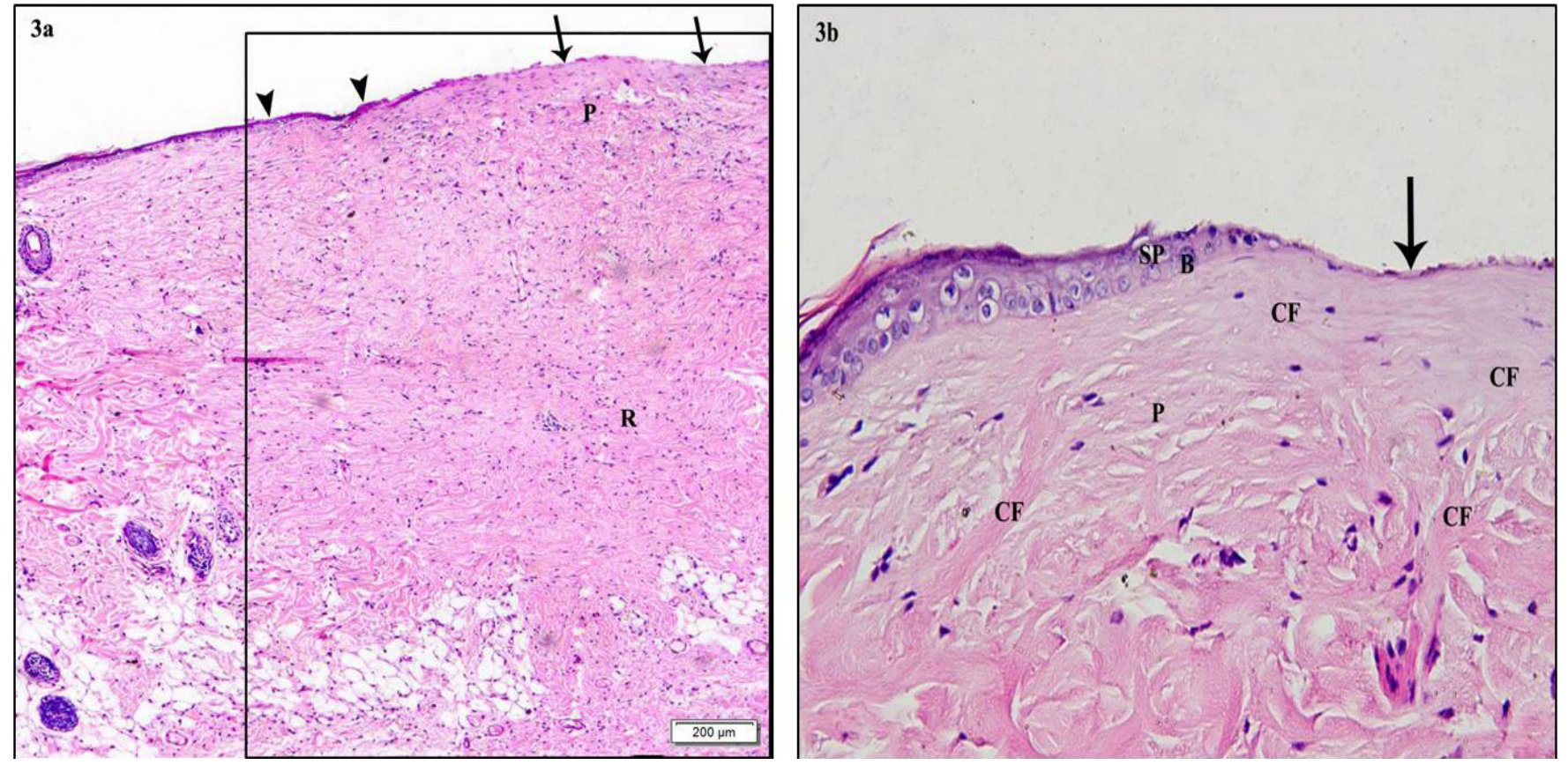

Fig. 3: Photomicrograph of skin section from a rat in group II (Excision wound group). (A) Area of granulation tissue (rectangle) reveals distorted epidermis formed of 1-3 cell layers without keratin (arrowheads) and another area shows completely lost epithelial covering leaving only exposed basal lamina (black arrows). The markedly thick dermis showed thick bundles of collagen fibers occupying both the papillary (P) and reticular layers (R). (B) Higher magnification shows distorted epidermis lined with 1-3 cell layers formed only of stratum basale (B) and stratum spinosum (SP), and another area shows completely lost epithelial covering leaving only exposed basal lamina (black arrow). The dermis showed thick bundles of collagen fibers (CF) occupying the papillary layer (P) (HandE, x100; x200)
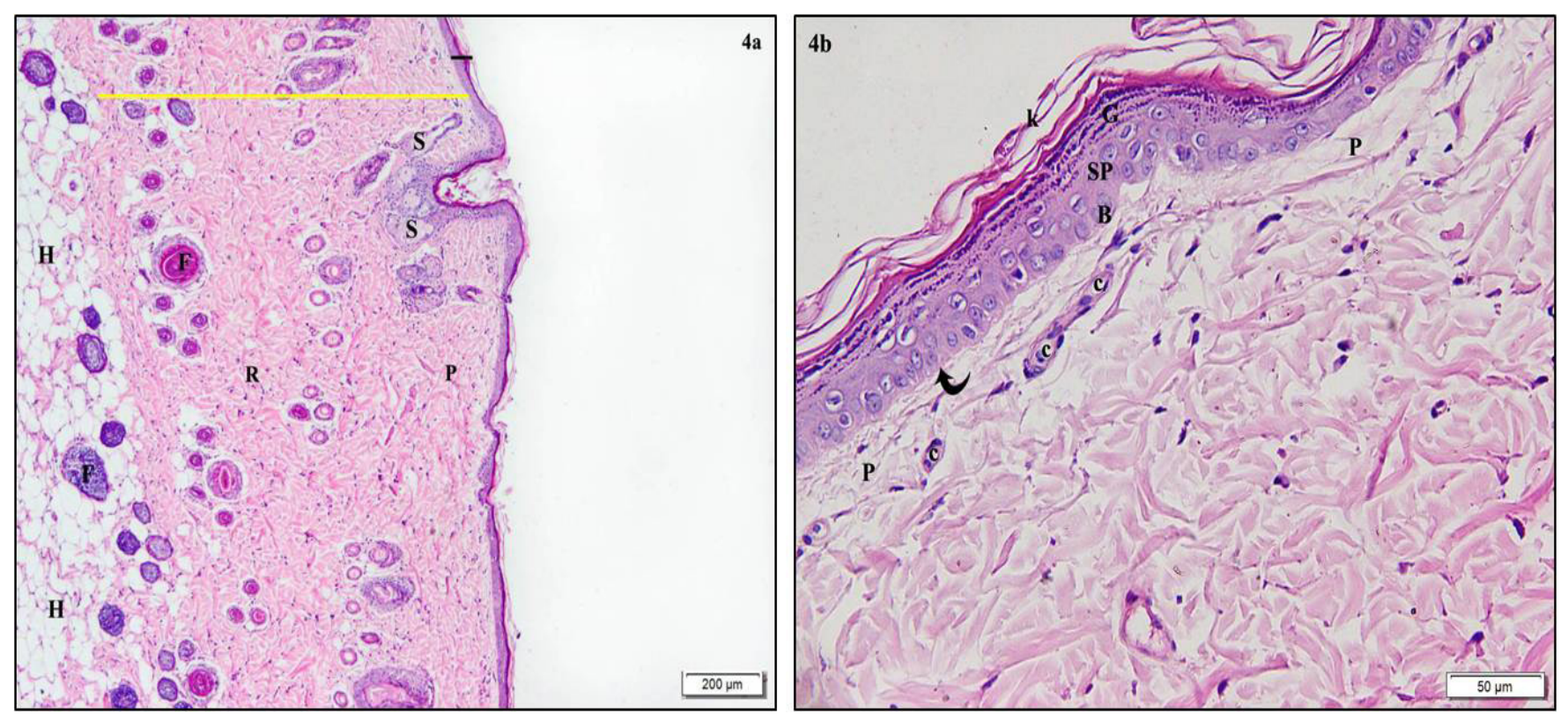

Fig. 4: Photomicrograph of skin section from a rat in group III (Exos-treated group). (A) Reveals apparently normal epidermis lined with keratinized stratified squamous epithelium (black line) and dermis (yellow line). The dermis displayed normal thickness, and consists of papillary (P) and reticular (R) layers. Sebaceous glands (S) and hair follicles (F) are seen in the dermis. The lower part is occupied by hypodermis (H) full of fat cells. (B) Higher magnification displays normal epidermis formed of stratum basale (B), 2-3 layers of stratum spinousum (SP), 2-3 layers of stratum granulosum (G) and keratin (K). Prominent dermal-epidermal junction (curved arrow) and numerous blood capillaries (c) in papillary layer (P) are seen

(HandE, x100; x200) 

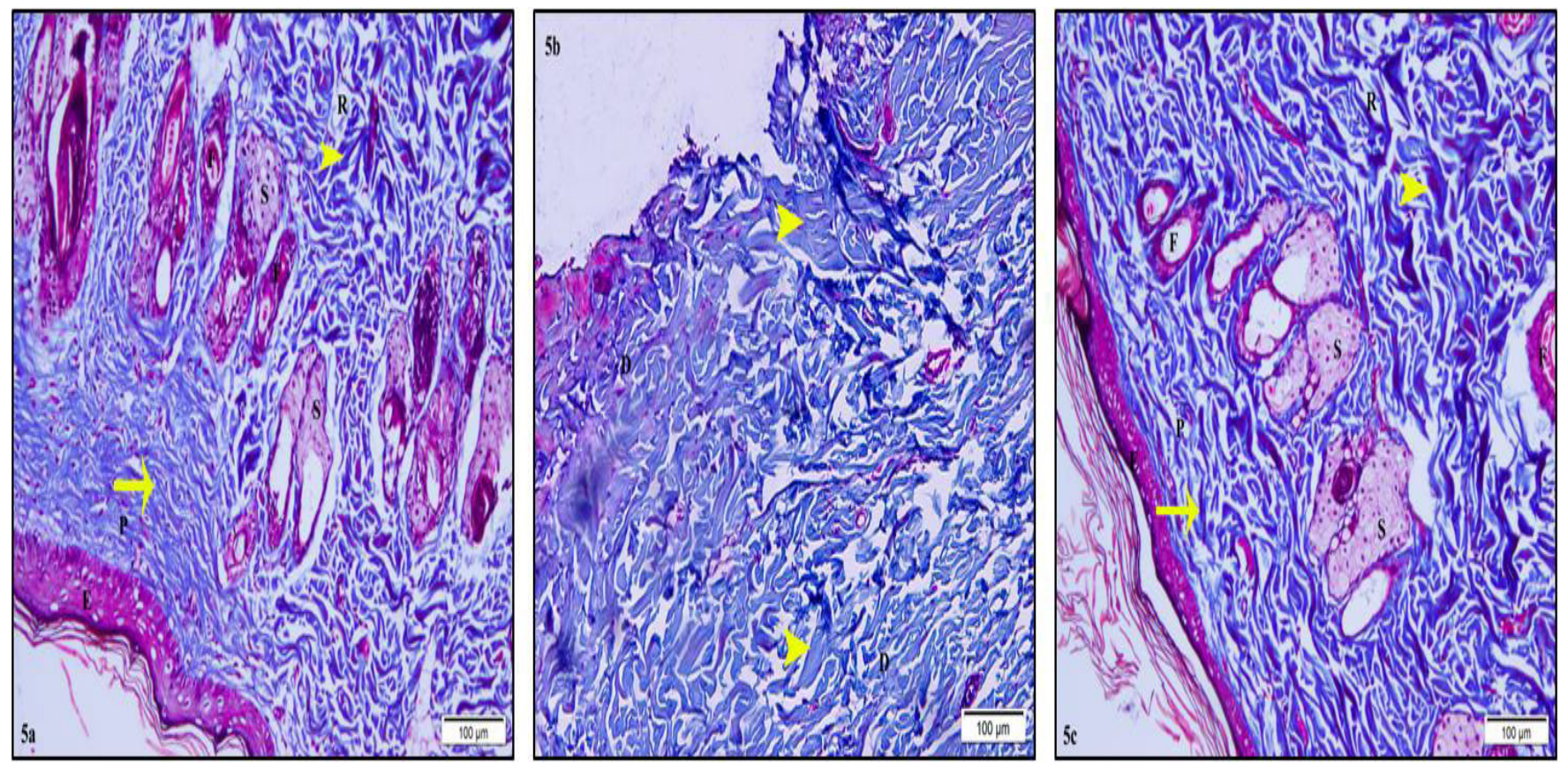

Fig. 5: Photomicrograph of skin sections stained with Mallory's trichrome stain. (A) Control rats show interlacing bundles of loosely arranged blue stained collagen fibers (yellow arrow) in the papillary dermis (P) and coarse, wavy irregular bundles (yellow arrowhead) in the reticular dermis (R). It is covered by epidermis (E). Sebaceous glands (S) and hair follicles (F) are seen in dermis. (B) Group II reveals dense thick coarse collagen bundles (yellow arrowhead) that occupied all the dermal thickness (D). There is no epidermal covering. (C) Group III exhibits thin bundles of collagen fibers (yellow arrow) in the papillary dermis $(\mathrm{P})$ and coarse thick collagen (yellow arrowhead) in the reticular layer $(\mathrm{R})$. The surface is covered by epidermis (E). Sebaceous glands (S) and hair follicles $(\mathrm{F})$ are seen in the dermis. (Mallory's trichrome, x200)
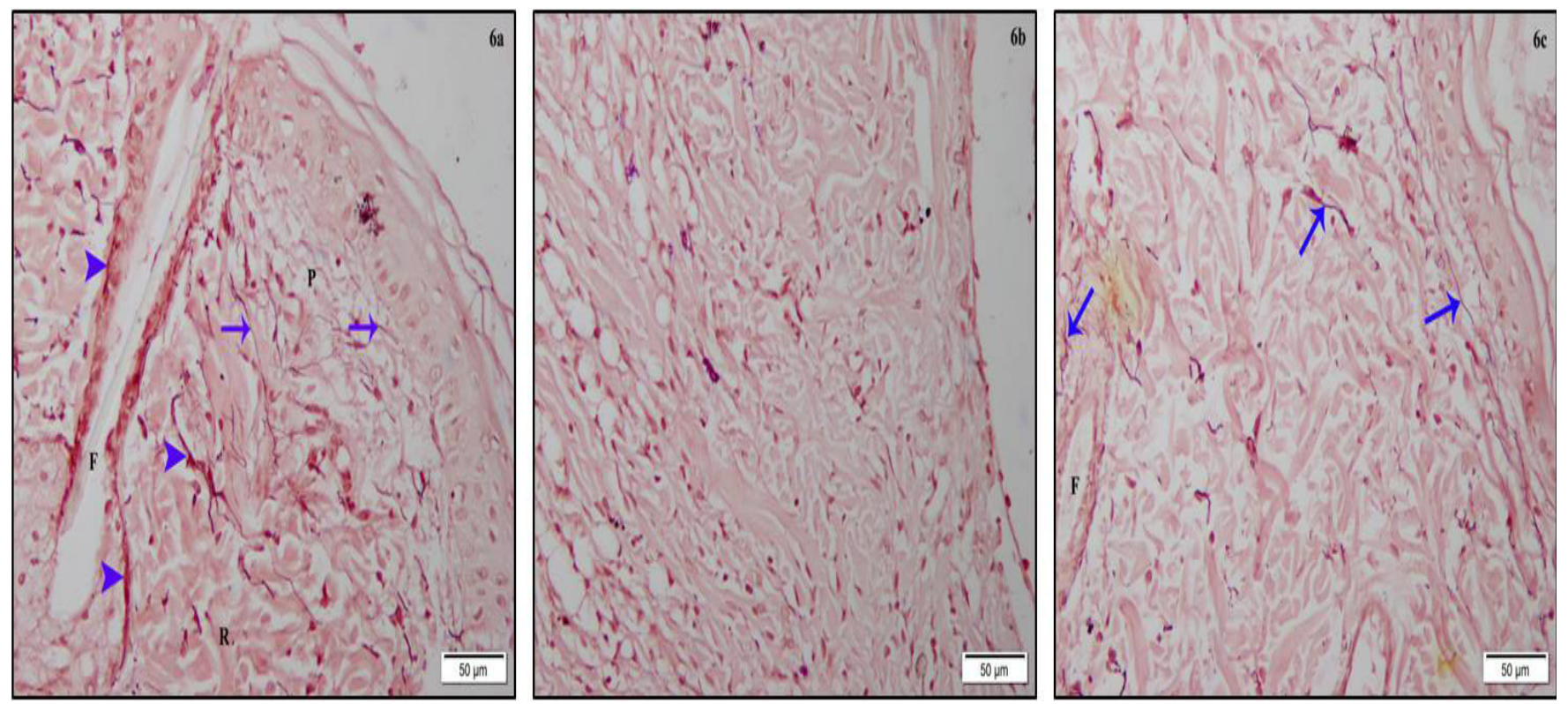

Fig. 6: Photomicrograph of skin sections stained with orcein stain. (A) Control rats show brick red thin elastic fibers (blue arrows) in the papillary dermis (P). They appeared longer, thicker and branched (blue arrowheads) in the reticular layer (R) and condensed around the hair follicles (F). (B) Group II reveals no apparent elastic fibers in the granulation tissue. (C) Group III displays fine interlacing network elastic fibers in the subepidermal area (blue arrows) and around hair follicles $(\mathrm{F})$

(Orcein, $\mathrm{x} 400$ ) 

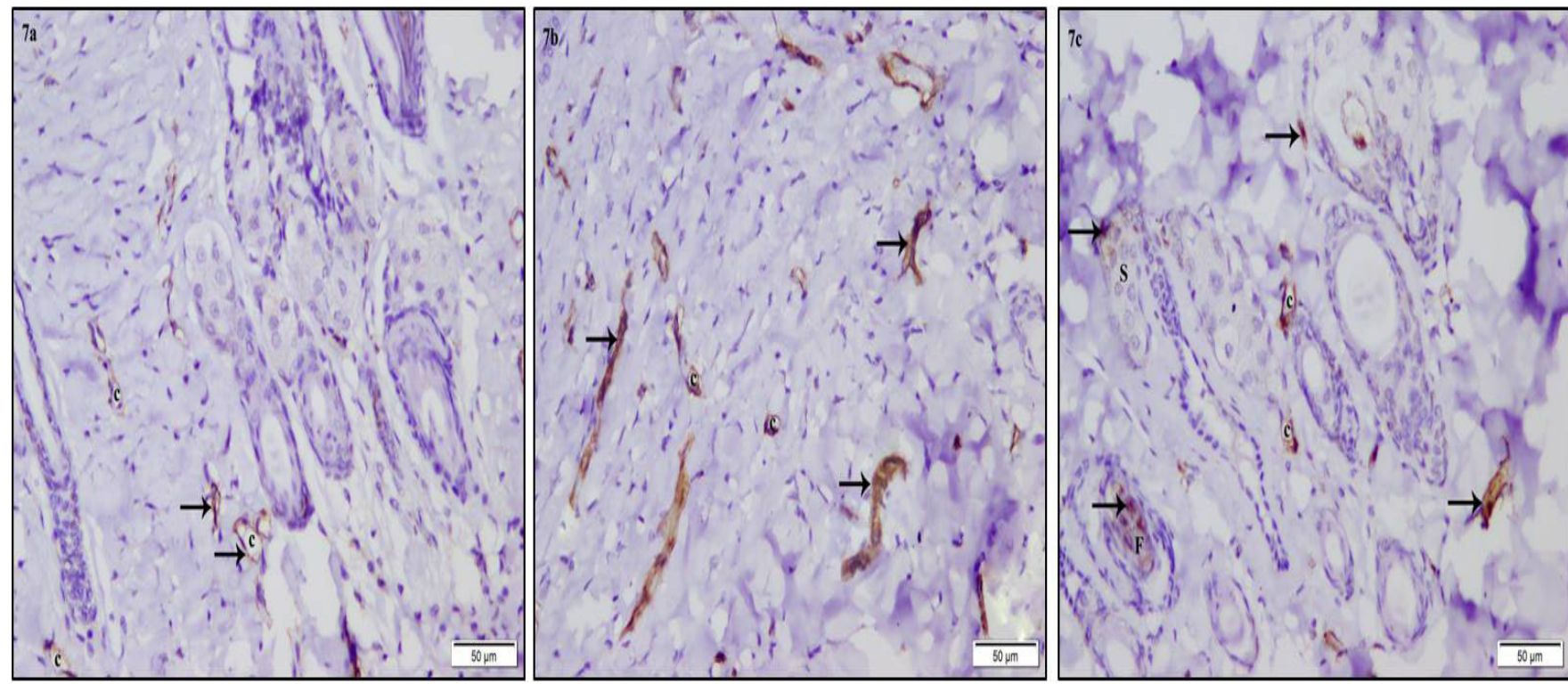

Fig. 7: Photomicrograph of skin sections stained with $\alpha$-SMA immunohistochemical stain. (A) Control rats reveal little brown cytoplasmic reaction (arrows) in the cells of skin dermis mainly surrounding capillaries (c). (B) Group II exhibits widespread cytoplasmic immunoexpression (arrows) within the dermis and around blood capillaries (c). (C) Group III show moderate cytoplasmic immunoreactive (arrows) in the dermal cells, some of which are related to capillaries (c), hair follicles (f) and sebaceous glands (s).

( $\alpha$ SMA immunohistochemical stain, $x 400)$
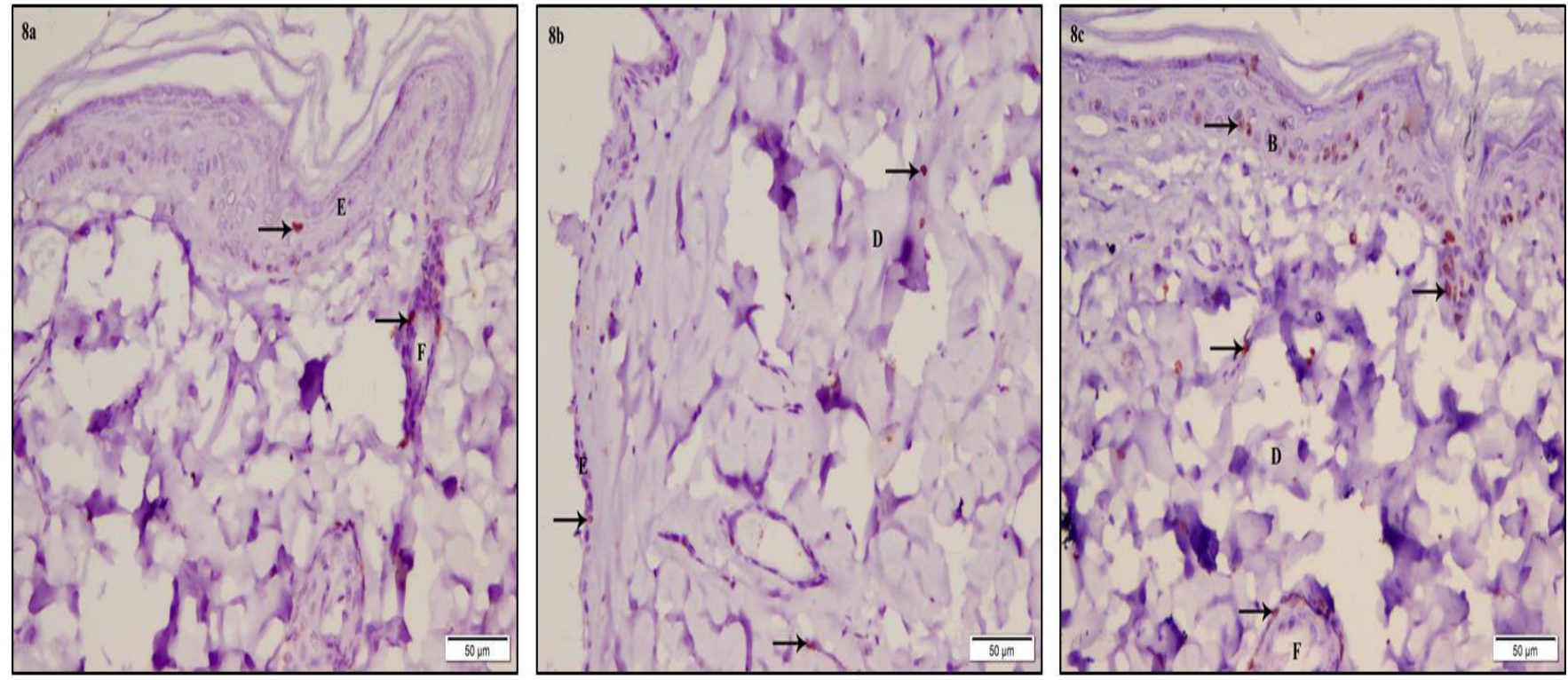

Fig. 8: Photomicrograph of skin sections stained with Ki67 immunohistochemical stain. (A) Control rats display scarce brown immunoreactive nuclei (arrows) in the cells of epidermis (E) and in the hair follicles (F). (B) Group II shows few immunoreactive cells in the thin epidermal layer (E) and the dermis (D). (C) Group III presents many brown nuclei (arrows) in the epidermal cells especially in the stratum basale (B), in the hairs follicles (F) and dermis (D).

(Ki67 immunohistochemical stain, $\mathrm{x} 400$ ) 


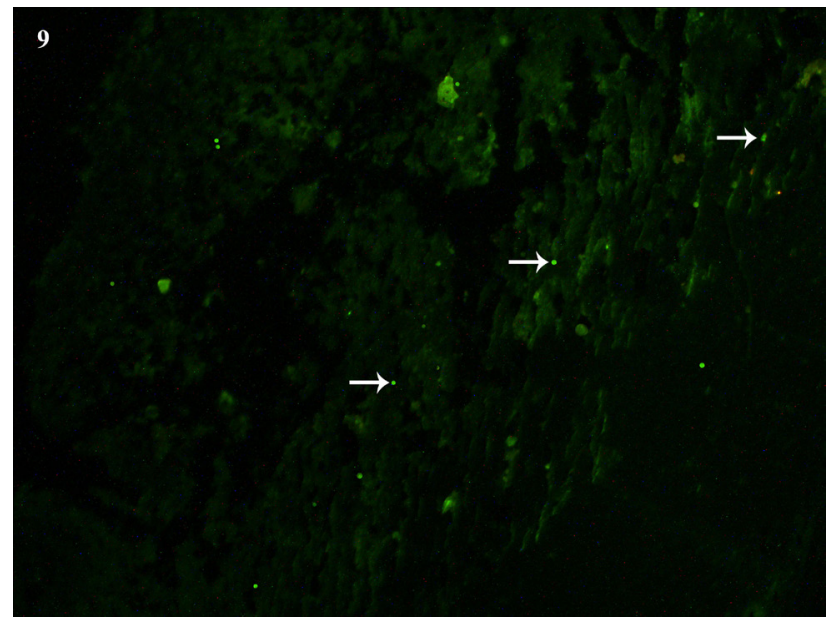

Fig. 9: Photomicrograph of an unstained section from group III (Exos-treated group) demonstrated homing of the PKH26 labeled Exos in the papillary and reticular layers of the dermis (arrows).

(Fluorescent staining, x200)

\section{DISCUSSION}

Because of the increasing prevalence of chronic wounds worldwide and their marked outcomes on patient's morbidity and mortality (let alone amputations), it is important to consider adequate and effective interventions to treat such debilitating wounds and to find a new safe, stable and efficient method to promote wound healing ${ }^{[21]}$. Hence, the current work examined the therapeutic benefits of adipose mesenchymal stem cells-derived exosomes (ASCs-Exos) on the healing of cutaneous full-thickness excision wounds in adult male albino rats, not only for accelerating the healing, but also for preventing scar formation. Day 21 was chosen as the end day of the experiment because previous studies reported this period was required for either healing of the wound or occurrence of chronic inflammatory response ${ }^{[22]}$.

In the present study, the wounded areas of the untreated group II presented with scar formation, inflammatory signs, and lost hair follicles. Microscopically, there was either very thin epithelial covering without keratin or complete epithelial loss, which was proved by the significant decrease in Ki67 immunoexpression. Also the dermis was markedly thickened and occupied by thick bundles of collagen fibers with no apparent elastic fibers. This was fatherly proved by the marked increase in area percent of collagen deposition, significant increased $\alpha$-SMA immunoexpression and almost disappearance of elastic fibers. In addition, blood vessels, hair follicles and sebaceous glands were absent in areas of granulation tissue. This is in agreement with other scientists who found remarkable defects in skin architecture, lost epithelial covering, hair follicles and blood vessels, with elevated collagen deposition and decreased elastic fibers following excision skin wound in rats ${ }^{[3 ; 23]}$.

Researchers have reported that the formation of pathological scar is mainly due to excessive collagen protein deposition ${ }^{[1]}$ and this could be correlated with the significant increase in $\alpha$-SMA immunoreaction; since fibroblasts (FBs) and myofibroblasts (MFs) play a crucial role during the healing process through secreting and remodelling the extracellular matrix mainly collagen proteins ${ }^{[24 ; 25]}$. In the early phases of wound healing, FBs proliferate and undergo phenotypic changes into MFs, these occur in response to mechanical tension and cytokines, especially transforming growth factor- $\beta$ that are produced by inflammatory cells migrated to the wound area. And result in increased collagen synthesis and contraction of wound edges ${ }^{[26 ; 24]}$. In the remodeling phase, collagen is constantly degraded to decrease wound thickness and brings the wound margins closer together ${ }^{[5]}$. Regarding the absent blood vessels, it was proved to occur during the inflammatory phase of wound healing to trigger the formation of a blood clot causing haemostasis ${ }^{[3]}$.

Although several investigations have focused on accelerating the wound healing process, definitive treatments are still unavailable. Recently, advances in stem cell transplantation have shown promising results in promoting skin wound healing. Both mesenchymal stem cells (MSCs) and embryonic stem cells (ESCs) have been studied and proved to be effective in improving wound healing when injected into wound sites, alone or in combination with biological materials ${ }^{[27]}$. Yet, the procedures involved in harvesting MSCs from adult tissues are invasive and their proliferation and differentiation capabilities are limited after several passages in culture. Besides, these capabilities decline significantly in age-related disorders or with increasing age ${ }^{[28]}$. Moreover, it was demonstrated that stem cell transplantation promotes wound healing primarily through a paracrine mechanism ${ }^{[29]}$, and that exosomes (Exos) play a key role in this mechanism ${ }^{[30]}$ since they contain proteins, mRNAs, and miRNAs that are released into the extracellular milieu, thus playing a significant role in intercellular communication ${ }^{[15]}$.

Cells secrete extracellular vesicles (EVs), namely, apoptotic bodies, microvesicles, and Exos, which have considerable impact on the local microenvironment and on distant tissues in the body. They carry diverse molecular constituents, including nucleic acids and proteins that differ according to the cell or tissue of origin. Consequently, they change the gene expression of recipient cells, regulating cell growth, division, and apoptosis ${ }^{[31]}$. Lately, Exos have gained attention as being the potential paracrine mediators of MSCs in numerous disease models. Results up to now have indicated that they could effectively repair the damage of acute kidney injury ${ }^{[32]}$, liver fibrosis ${ }^{[33]}$ and myocardial ischemia reperfusion injury ${ }^{[34]}$, promote functional recovery after stroke ${ }^{[35]}$ and ameliorate inflammation after Escherichia coli endotoxin-induced acute lung injury ${ }^{[36]}$. Subsequently, Exos were used in this study to explore their effects on wound healing.

In this study, adipose stem cells (ASCs) were used to extract Exos; fat tissue widely distributed in human body, 
contains a lot of mesenchymal stem cells and is an active endocrine organ that is thought to play an essential role in repairing soft tissue trauma ${ }^{[37]}$. Recently, fat tissue has been extensively studied for its role in wound repair. It is used to regenerate soft tissues in plastic surgery and its safety and efficacy are largely accepted ${ }^{[38]}$. Also, autologous adipose graft was applied to help in complicated wound repair, but there is lack of evidence for its mechanism ${ }^{[39]}$. In a previous study, conditioned medium of cultured ASCs was proved to promote migration, proliferation and collagen synthesis of fibroblasts and a number of Exos was extracted from this conditioned medium ${ }^{[13]}$.

In the present work, Exos were given to wounded rats in group III via intravenous injection and homing was examined at day 7 post-injection. This was done in accordance with Hu et al. ${ }^{[16]}$ who compared intravenous injection with local injection of Exos. Interestingly, they found that intravenous injection was superior at wound healing, and they hypothesized that loss of Exos during local injection may contribute to this difference. Moreover, when Exos are injected directly into the wound, unavoidably the wound can be further distorted, thus disrupting the wound healing process. They also stated the gathering of fluorescence at the wound area at day 7 , and then became weak and gradually disappeared. They explained that by the ability of Exos to recruit to the damaged area through receptors or adhesion molecules on the membrane surface, and targeted FBs to promote wound healing ${ }^{[16]}$. Moreover the disappearance of Exos could be explained by the fact that they meet one of three fates after their injection: (a) taken by cells in immediate proximity, (b) taken by cells distant from the cell of origin, or (c) removal by distant tissues after entering the systemic circulation ${ }^{[31]}$.

Group III (Exos-treated group) presented almost normal macroscopic picture; complete epidermal coverage with the presence of hairs. Examined skin sections showed improved epithelialization and keratinization, with restoration of skin appendages, and this was confirmed by the significant increase in Ki67 immunoexpression. These findings are consistent with other researches that were designed to study the efficacy of Exos on wound healing in rats ${ }^{[40 ; 7 ; 1]}$. Increased cell proliferation after Exos injection might be due to the inhibition of heat stress-induced apoptosis in keratinocytes and dermal FBs by reducing the level of pro-apoptotic protein $\mathrm{Bax}^{[40]}$. In addition, their lipid bilayer shell avoids proteolytic degradation, thus transferring signals more efficiently to target cells (eg, epithelial and endothelial cells). Also Exos contain many regulatory components including mRNAs, miRNAs and proteins, which can be transferred as a type of "physiological lipofection" to recipient cells to modify their characteristics. Furthermore, they cause activation of growth factor signaling cascades in target cells, which is largely important, since chronic wounds have attenuated signaling cascades and growth factor expression ${ }^{[41]}$.

Moreover, the underlying dermis in group III sections was of normal thickness and contained fine interlacing network of elastic fibers, with appearance of blood vessels. This was established by the significant decrease in collagen deposition, $\alpha$-SMA immunoexpression and the significant increase in elastic fibers. This is in agreement with previous studies exploring the effect of Exos on wound healing regardless their cells of origin $^{[15 ; 40 ; 16 ; 42 ; 7 ; 1]}$.

Neovascularization is essential in the process of wound healing to sustain the newly formed granulation tissue, the survival of keratinocytes and re-epithelialization ${ }^{[21]}$. The formation of new vessels requires the proliferation of endothelial cells, as well as the interaction between endothelial cells, angiogenic factors (such as vascular endothelial growth factor and fibroblast growth factor) and surrounding ECM proteins. In this matter Exos have proven to be beneficial by the fact that they can enhance the expression of these angiogenic factors ${ }^{[7]}$. Besides their capability to stimulate endothelial cells proliferation ${ }^{[41]}$.

Regarding the markedly decreased collagen fibers and increased area of elastic fibers, Exos have been proved to regulate ECM remodeling and stimulate the increase in elastin secretion ${ }^{[15]}$. Interestingly, Exos catalyze the cross linking of collagen via lysyl oxidase-like 2 (LOXL2) located on the exterior of their membranes ${ }^{[43]}$. However, in the late stage of wound healing, exosomes may inhibit collagen expression ${ }^{[16]}$. That is to say, Exos have significantly increased the healing rate and reduce scar widths $^{[44]}$.

Concerning the significant decrease $\alpha$-SMA immunoexpression, it was found that in the resolution phase of healing, the cell number of MFs is markedly reduced by apoptosis. Some authors mentioned that MFs disappear in a prominent wave of apoptosis, leaving a markedly less cellular scar ${ }^{[3]}$. Apoptosis in MFs is thought to be regulated by reduction in local growth factors that drive and sustain their differentiation as transforming growth factor and endothelin- $1^{[45]}$. Others wonder if MFs can reacquire a quiescent phenotype and return to normal dermal FBs with no expression of $\alpha$-SMA. However, in many fibrotic and scarring conditions, they fail to undergo cell death, persist, and thus in turn lead to ongoing pathology and scarring ${ }^{[46]}$.

Interest in using Exos in therapeutic approaches and evidence of their effectiveness is of increasing concern. They are regarded as a new delivery system for several curative agents and for cell-free approaches in regenerative medicine. Exos have a specific cell tropism, according to their characteristics, which can be used to target them to specific tissues and/or organs. Moreover, they can be engineered and/or loaded with several molecules (drugs, small molecules, nanoparticles) and targeted to specific organs, thus can be used for the delivery of therapeutic agents in a targeted manner while enhancing the stability of the molecular cargo and protecting it from metabolic degradation. However, the mechanisms by which Exos interact with target cells are still under investigations ${ }^{[47]}$. As alternatives to cellular therapies, Exos have advantages regarding safety and regulatory concerns; they do not 
have the replicative capacity of cells, less complex and more amenable to quality control and expand more when compared to cells. Furthermore, they have the potential to be used as drug carriers and could be uniquely employed in personalized medicine if obtained from the patient's own cells. Thus, in addition to increased knowledge of Exos biology, the fields of regenerative medicine and tissue engineering may benefit from advances in Exos-related biotechnology ${ }^{[48]}$

\section{CONCLUSION}

This study provides evidence that ASCs-Exos have significantly promoted wound healing and inhibited scar formation in skin full-thickness excision wound in albino rats. This could pave the way for their use in clinical practice as a cell-free therapy for different diseases that require tissue regeneration. Nevertheless, there are several issues to be considered before their application to patients. Among these, understanding organ or tissue specific tropism of different sub-populations of Exos, the efficacy of targeting strategies, the mechanisms of their uptake into the cells, besides, developing cost effective improved methods for Exos generation to be used in humans.

\section{CONFLICT OF INTEREST}

The authors have no conflicting financial interest.

\section{REFERENCES}

1. Zhao B, Zhang Y, Han S, Zhang W, Zhou Q, Guan H, Liu J, Shi J, Su L, Hu D. Exosomes derived from human amniotic epithelial cells accelerate wound healing and inhibit scar formation. J Mol Histol. 2017; 48(2):121-132

2. Guo SA, di Pietro LA. Factors affecting wound healing. J. Dent. Res. 2010; 89(3): 219-229.

3. Darby IA, Laverdet B, Bonté F, Desmoulière A. Fibroblasts and myofibroblasts in wound healing. Clinical, Cosmetic and Investigational Dermatology. 2014; 7: 301-311.

4. Sandbo N, Dulin N. Actin cytoskeleton in myofibroblast differentiation: ultrastructure defining form and driving function. Transl Res. 2011; 158(4):181-196.

5. Rani S, Ritter T. The exosome - a naturally secreted nanoparticle and its application to wound healing. Adv. Mater. 2016; 28(27): 5542-5552.

6. Wong E, Nahar N, Hau E, Varikatt W, Gebski V, $\mathrm{Ng}$ T, Jayamohan J, Sundaresan P. Cut-point for $\mathrm{Ki}-67$ proliferation index as a prognostic marker for glioblastoma. Asia-Pac J Clin Oncol. 2018; 1-5.

7. Than UTT, Guanzon D, Leavesley D, Parker T. Association of Extracellular Membrane Vesicles with Cutaneous Wound Healing. Int J Mol Sci. 2017; 18(5): pii: E956.
8. Harrison P, Gardiner C, Sargent IL. Extracellular vesicles in health and disease. Pan Stanford Publishing; Hoboken, NJ, USA: 2014, pp: 3-4.

9. Sluijter JP, Verhage V, Deddens JC, van den Akker F, Doevendans PA. Microvesicles and exosomes for intracardiac communication. Cardiovasc Res. 2014; 102(2): 302-311.

10. Waldenstrom A, Ronquist G. Role of exosomes in myocardial remodeling. Circulation research. 2014; 114(2): 315-324.

11. Januszyk K, Lima CD. The eukaryotic RNA exosome. Current opinion in structural biology. 2014; 24: 132-140.

12. $\mathrm{Hu} \mathrm{L}, \mathrm{Hu} \mathrm{J}$, Zhao J, Liu J, Ouyang W, Yang C, Gong N, Du L, Khanal A, Chen L. Side-by-side comparison of the biological characteristics of human umbilical cord and adipose tissue derived mesenchymal stem cells. Biomed Res Int. 2013; 2013: 438243.

13. Hu L, Zhao J, Liu J, Gong N, Chen L. Effects of adipose stem cell-conditioned medium on the migration of vascular endothelial cells, fibroblasts and keratinocytes. Exp Ther Med. 2013; 5(3): 701706 .

14. Wu Y, Deng W, Klinke DJ. Exosomes: Improved methods to characterize their morphology, RNA content, and surface protein biomarkers. The Analyst. 2015; 140(19): 6631-6642.

15. Zhang J, Guan J, Niu X, Hu G, Guo S, Li Q, Xie Z, Zhang $\mathrm{C}$, Wang Y. Exosomes released from human induced pluripotent stem cells-derived MSCs facilitate cutaneous wound healing by promoting collagen synthesis and angiogenesis. Journal of Translational Medicine. 2015; 13:49-62.

16. Hu L, Wang J, Zhou X, Xiong Z, Zhao J, Yu R, Huang F, Zhang H, Chen L. Exosomes derived from human adipose mesenchymal stem cells accelerates cutaneous wound healing via optimizing the characteristics of fibroblasts. Sci Rep. 2016; 12(6): 32993.

17. Luo W, Jia Y, Zheng S, Li Y, Han J, Meng X. Changes in the action potential and transient outward potassium current in cardiomyocytes during acute cardiac rejection in rats. Journal of Thoracic Disease. 2017; 9(1):129-137.

18. Bancroft $\mathrm{J}$ and Gamble M: Theory and Practice of Histological Techniques. 7th ed., staining methods, Churchill Livingstone, Edinburgh, London, Madrid, Melbourne, New York and Tokyo. 2008; pp: $121-135$ and $263-325$.

19. Suvarna SK, Layton C, Bancroft JD: Bancroft's theory and practice of histological techniques, 7thedition .Elsevier Health sciences, Churchill 
Livingstone. 2012; pp. 215- 239.

20. Emsley R, Dunn G, White IR. Mediation and moderation of treatment effects in randomised controlled trials of complex interventions. Stat. Methods Med. Res. 2010; 19: 237-270.

21. De Mayo T, Conget P, Becerra-Bayona S, Sossa CL, Galvis V, Arango-Rodríguez ML. The role of bone marrow mesenchymal stromal cell derivatives in skin wound healing in diabetic mice. Fiorina $P$, ed. PLoS ONE. 2017; 12(6): e0177533.

22. Santos RMF dos, Sampaio CPP, Moraes DP de, Lima RL de. Evaluation of the effects of bismuth subgallate on wound healing in rats. Histological findings. International Archives of Otorhinolaryngology. 2016; 20(4):377-381

23. Li H, Duann P, Lin P-H, Zhao L, Fan Z, Tan T, Zhou X, Sun M, Fu M, Orange M, Sermersheim M, Ma H, He D, Steinberg SM, Higgins R, Zhu H, John E, Guan J, Ma J. Modulation of wound healing and scar formation by mg53 proteinmediated cell membrane repair. J. Biol. Chem. 2015; 290: 24592-24603

24. Xue M, Jackson CJ. Extracellular matrix reorganization during wound healing and its impact on abnormal scarring. Advances in Wound Care. 2015; 4(3):119-136.

25. Merjaneh $\mathrm{M}$, Langlois A, Larochelle S, Cloutier CB, Ricard-Blum S, Moulin VJ. Pro-angiogenic capacities of microvesicles produced by skin wound myofibroblasts. Angiogenesis. 2017; 20(3): 385-398.

26. Vedrenne N, Coulomb B, Danigo A, Bonte F, and Desmouliere A: The complex dialogue between (myo)fibroblasts and the extracellular matrix during skin repair processes and ageing. Pathol Biol (Paris). 2012; 60(1):20-27.

27. Nakamura Y, Ishikawa H, Kawai K, Tabata Y, Suzuki S. Enhanced wound healing by topical administration of mesenchymal stem cells transfected with stromal cell-derived factor-1. Biomaterials. 2013; 34:9393-400.

28. Zaim M, Karaman S, Cetin G, Isik S. Donor age and long-term culture affect differentiation and proliferation of human bone marrow mesenchymal stem cells. Ann Hematol. 2012; 91:1175-86.

29. Liang X, Ding Y, Zhang Y, Tse HF, Lian Q. Paracrine mechanisms of Mesenchymal Stem cellbased therapy: Current status and perspectives. Cell Transplant. 2014; 23(9):1045-59.

30. Baglio SR, Pegtel DM, Baldini N. Mesenchymal stem cell secreted vesicles provide novel opportunities in (stem) cell-free therapy. Front Physiol. 2012; 3:359-369.
31. Inamdar S, Nitiyanandan R, Rege K. Emerging applications of exosomes in cancer therapeutics and diagnostics. Bioengineering and Translational Medicine. 2017; 2(1):70-80.

32. Zhou, $\mathrm{Y} \mathrm{Xu} \mathrm{H,} \mathrm{Xu} \mathrm{W,} \mathrm{Wang} \mathrm{B,} \mathrm{Wu} \mathrm{H,} \mathrm{Tao} \mathrm{Y,}$ Zhang B, Wang M, Mao F, Yan Y, Gao S, Gu H, Zhu W, Qian H. Exosomes released by human umbilical cord mesenchymal stem cells protect against cisplatin-induced renal oxidative stress and apoptosis in vivo and in vitro. Stem Cell Res Ther. 2013; 4(2): 34-46

33. Li T, Yan Y, Wang B, Qian H, Zhang X, Shen L, Wang M, Zhou Y, Zhu W, Li W, Xu W. Exosomes derived from human umbilical cord mesenchymal stem cells alleviate liver fibrosis. Stem Cells Dev. 2013; 22(6): 845-854 (2013).

34. Sahoo S, Losordo DW. Exosomes and cardiac repair after myocardial infarction. Circulation research. 2014; 114(2): 333-344.

35. Xin H, Li Y, Cui Y, Yang JJ, Zhang ZG, Chopp M. Systemic administration of exosomes released from mesenchymal stromal cells promote functional recovery and neurovascular plasticity after stroke in rats. J Cereb Blood Flow Metab. 2013; 33:1711-1715

36. Zhu YG, Feng XM, Abbott J, Fang XH, Hao Q, Monsel A, Qu JM, Matthay MA, Lee JW. Human mesenchymal stem cell microvesicles for treatment of Escherichia coli endotoxin-induced acute lung injury in mice. Stem Cells. 2014; 32:116-125

37. Hiroshi Mizuno MT, Cagri Uysal A. Concise Review: Adipose-Derived Stem Cells as a Novel Tool for Future Regenerative Medicine. Stem cells. 2012; 30, 804-810

38. Eun SC. Stem cell and research in plastic surgery. Journal of Korean medical science. 2014; 29(3): S167-S169

39. Caviglia H, Landro ME, Gallo E, Douglas Price AL, Galatro G, Neme D. Is it possible to use autologous adipose graft for wound repair in patients with coagulation disorders? Haemophilia 2016; 22(2): 298-302

40. Zhang B, Wang M, Gong A, Zhang X, Wu X, Zhu Y, Shi H, Wu L, Zhu W, Qian H, Xu W. HucMSCExosome Mediated-Wnt4 Signaling Is Required for Cutaneous Wound Healing. Stem Cells. 2015; 33(7):2158-2168

41. Shabbir A, Cox A, Rodriguez-Menocal L, Salgado M, Badiavas EV. Mesenchymal Stem Cell Exosomes Induce Proliferation and Migration of Normal and Chronic Wound Fibroblasts, and Enhance Angiogenesis In-Vitro. Stem Cells and Development. 2015; 24(14): 1635-1647. 
42. Li X, Jiang C, Zhao J. Human endothelial progenitor cells-derived exosomes accelerate cutaneous wound healing in diabetic rats by promoting endothelial function. J Diabetes Complications. 2016; 30(6):986-992

43. Jong OG, Balkom BW, Gremmels H, Verhaar MC. Exosomes from hypoxic endothelial cells have increased collagen crosslinking activity through up-regulation of lysyl oxidase-like 2. J. Cell. Mol. Med. 2016; 20:342-350.

44. Guo SC, Tao SC, Yin WJ, Qi X, Yuan T, Zhang $\mathrm{C}-\mathrm{Q}$. Exosomes derived from platelet-rich plasma promote the re-epithelization of chronic cutaneous wounds via activation of YAP in a diabetic rat model. Theranostics. 2017; 7(1):81-96

45. Kulasekaran P, Scavone CA, Rogers DS, Arenberg DA, Thannickal VJ, Horowitz JC. Endothelin-1 and transforming growth factor-betal independently induce fibroblast resistance to apoptosis via AKT activation. Am J Respir Cell Mol Biol. 2009; 41(4):484-493.

46. van der Veer WM, Bloemen MC, Ulrich MM, Molema G, van Zuijlen PP, Middelkoop E, Niessen FB. Potential cellular and molecular causes of hypertrophic scar formation. Burns. 2009; 35(1):15-29

47. Corrado C, Raimondo S, Chiesi A, Ciccia F, De Leo G, Alessandro R. Exosomes as Intercellular Signaling Organelles Involved in Health and Disease: Basic Science and Clinical Applications. International Journal of Molecular Sciences. 2013; 14(3):5338-5366

48. Lamichhane TN, Sokic S, Schardt JS, Raiker RS, Lin JW, Jay SM. Emerging Roles for Extracellular Vesicles in Tissue Engineering and Regenerative Medicine. Tissue Engineering Part B, Reviews. $2015 ; 21(1): 45-54$ 
الملخص العربى

التقييم النسيجي للاور البارز للإكسوسومات المشتقة من الخلايا الجذعية الدهنية في علاج الجروح الجلاية في الجرذان البيضاء

\author{
داليا ابر اهيم اسماعيل والشيماء جمال أبوالخير

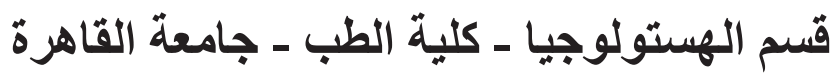

الخلفية: الجلد هو أكبر عضو وقائى في الجسم ، ولكنه يصاب في كثثير من الأحيان إما بجروح حادة أو مزمنة. يشكل الالتئام

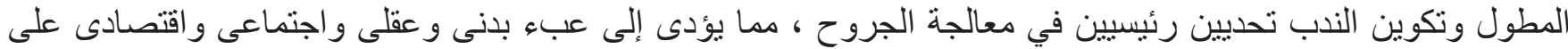

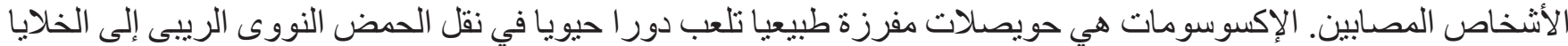

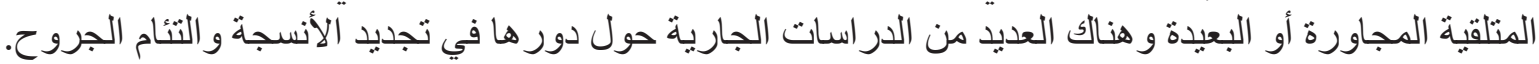

الهُف: تقييم كفاءة الإكسوسومات المستمدة من الخلايا الجذعية الثحمية على التئام الجروح الجلدية في ذكور الجرذان البيضاء.

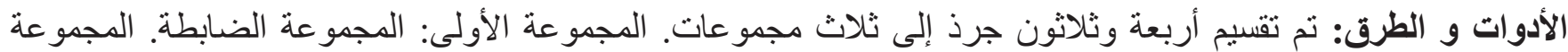

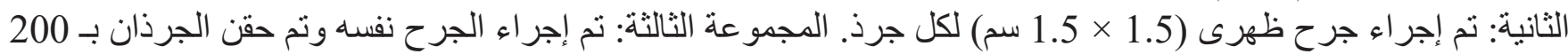

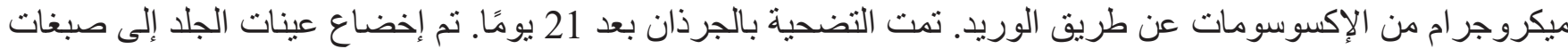

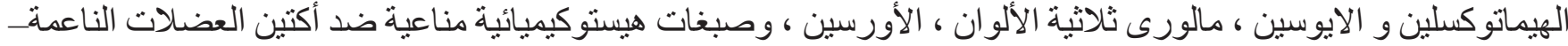

الفا ، وضد كأي أي 67

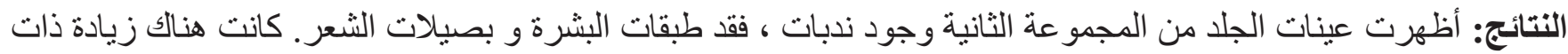

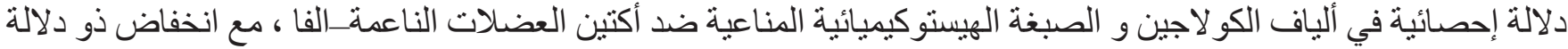

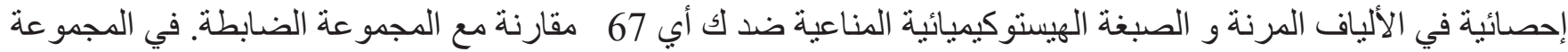

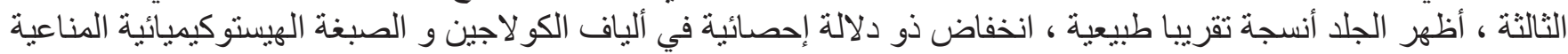

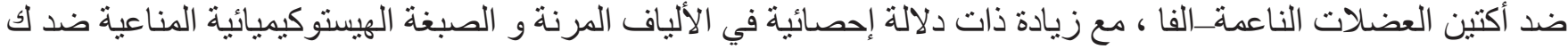
أي 67 مقارنة بالمجمو عة الثانية.

الخلاصة: أظهر حقن الإكسوسومات تأثير نافع على التثئام الجروح الجلدية ويمكن أن يمنع تكوين الندب في ذكور الجرذان البيضاء البالغة. 